\title{
Judging Equivalence for Sets of Functional Dependencies Based on Truth Table
}

\author{
Yishun Zhang \\ College of Computer and Information Engineering \\ ZheJiang GongShang University \\ Hangzhou, China \\ zys@mail.zjgsu.edu.cn
}

\begin{abstract}
Data dependencies theory is the basic tool for analyzing and designing of relational database. How to Judge whether two sets of functional dependencies are equivalent? This is a basic and important problem solved by using Armstrong's axioms in data dependencies theory. In this paper we shall point out that the rules of inference in Armstrong's axioms system and propositional inference in mathematical logic are consistent. This implies that If each functional dependency is viewed as conditional proposition, equivalent sets of functional dependencies have the same truth table in mathematical logic, so we can judge equivalence of two set of functional dependencies by truth table.
\end{abstract}

Keywords-relational database; set of functional dependencies; Armstrong's axioms; mathematical logic; truth table

\section{INTRODUCTION}

Nowadays various relational database application systems are being used widely. Relational database systems use relational model to organize data. In 1970 E.F.Codd [1] first put forward relational model, in which functional dependency(FD) is an very important concept which reflects restriction between attributes and play an important role in designing and analysis of database. Armstrong's axioms [2] system contains a set of rules of inference, by which a FD implied in a set of FDs can be derived. Two sets of FDs are equivalent if every FD in one set can be derived in the aother. This definition gives an approach to judge equivalence directly between two sets of FDs. But the approach is often time-consuming because of verifying whether two sets of FDs imply each other .

Mathematical logic studies reasoning .It is specifically concerned with whether reasoning is correct. Proposition logic is a basic portion of mathematical logic, It explores proposition and proposition inference. Atomic proposition is its smallest makeup unit and can't be divided anymore.

There have been some discussions on the relation between Armstrong's axioms system and mathematical logic ${ }^{[3-8]}$. It is demonstrated that most theorems on data dependencies can be transformed into counterparts and proved in mathematical logic

In this paper the theory and methods about proposition logic are used to study FD theory. Under the circumstances a FD is regarded as a conditional proposition in proposition logic, and every rule of inference in Armstrong's axioms has it's corresponding rule of proposition inference. This demonstrates that two propositions which correspond to two equivalent sets of FDs have the same truth table in mathematical logic.

\section{RELATIVE KNOWLEDGE}

\section{A. Functional Dependency}

Definition $1 \mathrm{U}$ is a set of attributes and $\mathrm{F}$ is a set of FDs over $\mathrm{U}, \quad X \subseteq U, X_{F}^{+}=\{A \mid X \rightarrow A$ can be derived from $\mathrm{F}$ by Armstrong axioms $\}, X_{F}^{+}$is called as closure of $\mathrm{X}$ under F.

Definition 2 Let $F$ be a set of FDs. The closure of F, written $F^{+}$, is the smallest set containing $F$ such that Armstrong's axiom cannot be applied to the set to yield a FD which is not in the set.

Definition 3 Two sets of FDs $F$ and $G$ are equivalent, written $\mathrm{F} \equiv \mathrm{G}$, if $F^{+}=G^{+}$. If $\mathrm{F} \equiv \mathrm{G}$, then $\mathrm{F}$ is a cover for $\mathrm{G}$, and $\mathrm{G}$ is a cover for $\mathrm{F}$.

Lemma $1 F \equiv G$ if and only if $F \subseteq G^{+}$and $G \subseteq F^{+}$

To test $F \subseteq G^{+}$, the common way is that for every FD $X \rightarrow Y \in F$, verifying whether $\mathrm{Y}$ belongs to $X_{G}^{+}$. This approach is simple and directly, but is often time-consuming because of computing closure of left side of every FD.

\section{B. Propositional Logic}

Definition 4 A sentence that is either true or false, but not both is called a proposition. $\mathrm{T}$ denoting true and $\mathrm{F}$ denoting false

Uppercase letters, such as A, B, and C, are used to represent propositions.

Definition 5 There are two forms of proposition, one is atomic proposition which can not be decomposed into more simple sentence, the other is compound proposition which is made up of atomic propositions and connectives

Definition 6 Truth table of a proposition P made up of the individual proposition. Lists all possible combinations of truth values for every propositions, and for each such combination lists the truth value of $\mathrm{P}$.

Let $\mathrm{P}$ and $\mathrm{Q}$ be propositions, following are several important connectives

Negation

The negation of $\mathrm{P}$, denoted $\neg P$, is the proposition not $P$ 
TABLE I. TRUTH TABLE OF $\neg P$

\begin{tabular}{|l|l|}
\hline $\mathrm{P}$ & $\neg P$ \\
\hline $\mathbf{T}$ & $\mathbf{T}$ \\
\hline $\mathbf{F}$ & $\mathbf{F}$ \\
\hline
\end{tabular}

TABlE II. TRUth TABle of $P \wedge Q, P \vee Q, P \rightarrow Q$

\begin{tabular}{|c|c|c|c|c|}
\hline $\mathbf{P}$ & $\mathbf{Q}$ & $P \wedge Q$ & $P \vee Q$ & $P \rightarrow Q$ \\
\hline $\mathbf{F}$ & $\mathbf{F}$ & $\mathbf{F}$ & $\mathbf{F}$ & $\mathbf{T}$ \\
\hline $\mathbf{F}$ & $\mathbf{T}$ & $\mathbf{F}$ & $\mathbf{T}$ & $\mathbf{T}$ \\
\hline $\mathbf{T}$ & $\mathbf{F}$ & $\mathbf{F}$ & $\mathbf{T}$ & $\mathbf{F}$ \\
\hline $\mathbf{T}$ & $\mathbf{T}$ & $\mathbf{T}$ & $\mathbf{T}$ & $\mathbf{T}$ \\
\hline
\end{tabular}

The truth value of the proposition $\neg P$ is defined by the table 1

Conjunction

The conjunction of $P$ and $Q$, denoted $P \wedge Q$, is the compound proposition

$$
P \text { and } Q
$$

and defined by the table 2

Disjunction

The disjunction of $P$ and $Q$, denoted $P \vee Q$, is the compound proposition

$$
P \text { or } Q
$$

and defined by the truth table 2

Conditional proposition

If $\mathrm{P}$ and $\mathrm{Q}$ are propositions, the compound proposition if $P$ then $Q$

is called a conditional proposition and is denoted $P \rightarrow Q$, and defined by the truth table 2 , the proposition $\mathrm{P}$ is called the hypothesis and the proposition $\mathrm{Q}$ is called theconclusion.

Definition 7 Suppose that the compound proposition $\mathrm{P}$ and $\mathrm{Q}$ are made up of the propositions $P_{1}, P_{2}, \cdots, P_{n}$. P and $\mathrm{Q}$ are logically equivalent and write $P \Leftrightarrow Q$, provided that given any truth values of $P_{1}, P_{2}, \cdots, P_{n}$, either $\mathrm{P}$ and $\mathrm{Q}$ are both true or $\mathrm{P}$ and $\mathrm{Q}$ are both false.

Definition 8 Suppose that the compound proposition $P$ and $\mathrm{Q}$ are made up of the propositions $P_{1}, P_{2}, \cdots, P_{n}$. No matter what truth values are assigned to $P_{1}, P_{2}, \cdots, P_{n}, P \rightarrow Q$ is always true . we call " $P$ implies $Q$ ", and denoted $P \Rightarrow Q$

Lemma $2 P \Leftrightarrow Q$ if and only if $P \Rightarrow Q$ and $Q \Rightarrow P$

\section{CONSISTENCY BETWEEN ARMSTRONG'S AXIOMS AND PROPOSITIONAL LOGIC}

FD is not only similar to conditional proposition formally but also plays a same role in Armstrong's axioms just as conditional proposition in propositional logic. If we regard a FD as a conditional proposition, we can immediately find that every rule of inference in Armstrong's axioms has corresponding rule in propositional logic. In fact ,these corresponding rules are just only a subset of all inference rules in propositional logic, so the following theorem can be obtained at once.

Theorem $G=\left\{F D_{1}, F D_{2}, \cdots, F D_{n}\right\}$ is a given set of FDs and $X \rightarrow Y \in G^{+}$, if each FD in G is regarded as conditional propositions, then $F D_{1} \wedge F D_{2} \wedge \cdots \wedge F D_{n} \Rightarrow X \rightarrow Y$

Proof: The keypoint is to show that every rule of inference in Armstrong's axioms has corresponding implication formula in proposition logic

Suppose F is a set of FDs over attributes U, Armstrong's axioms contain the following rules of inference:

Reflexivity: if $Y \subseteq X \subseteq U$, then $X \rightarrow Y$ is implied by F.

Augmentation: if $X \rightarrow Y$ is implied by F, and $Z \subseteq U$, then $X Z \rightarrow Y Z$ is implied by $\mathrm{F}$

Transitivity: if $X \rightarrow Y$ and $Y \rightarrow Z$ are implied by F, then $X \rightarrow Z$ is implied by $\mathrm{F}$

These three rules of inference have following corresponding implication formulas respectively in logic.

$$
\begin{aligned}
& A \wedge B \Rightarrow A \leftrightarrow \text { Reflexivity } \\
& A \rightarrow B \Rightarrow(A \wedge C) \rightarrow(B \wedge C) \leftrightarrow \text { Augmentation } \\
& (A \rightarrow B) \wedge(B \rightarrow C) \Rightarrow A \rightarrow C \leftrightarrow \text { Transitivity }
\end{aligned}
$$

So if $X \rightarrow Y$ as a FD can be derived by Armstrong's axioms then as a conditional proposition it can also be derived in proposition logic.

Example 1: $G=\{B \rightarrow C, C D \rightarrow E\}$ is a set of FDs, prove $A B D \rightarrow E \in G^{+}$, the corresponding logic language is to prove $(B \rightarrow C) \wedge((C \wedge D) \rightarrow E) \Rightarrow(A \wedge B \wedge D) \rightarrow E$

The following is a derivation sequence in Armstrong's axioms(left) and logic(right) respectively
1. $B \rightarrow C$
(given)
$B \rightarrow C$
2. $B D \rightarrow C D \quad$ (Augmentation) $B \wedge D \rightarrow C \wedge D$
3. $C D \rightarrow E \quad$ (given) $\quad C \wedge D \rightarrow E$
4. $B D \rightarrow E \quad$ (Transitivity) $B \wedge D \rightarrow E$
5. $A B D \rightarrow B D$ (Reflexivity) $\quad A \wedge B \wedge D \rightarrow B \wedge D$
6. $A B D \rightarrow E$ (Transitivity) $A \wedge B \wedge D \rightarrow E$

Corollary: $F=\left\{F D_{1}, F D_{2}, \cdots, F D_{m}\right\}$ and $G=\left\{F D_{1}^{\prime}, F D_{2}^{\prime}, \cdots, F D_{n}^{\prime}\right\}$ are two sets of FDs, if $F \equiv G$ then $F D_{1} \wedge F D_{2} \wedge \cdots \wedge F D_{m} \Leftrightarrow F D_{1}^{\prime} \wedge F D_{2}^{\prime} \wedge \cdots \wedge F D_{n}^{\prime}$. From the corollary we come to a conclusion: two sets of FDs are equivalent if and only if their truth table are same.

Example 2: Given the following two sets of FDs:

$$
\begin{gathered}
F_{1}=\{A B \rightarrow D, C D \rightarrow B, C D \rightarrow A, A \rightarrow B, D \rightarrow C\} \\
F_{2}=\{A \rightarrow D, D \rightarrow B, A \rightarrow C, D \rightarrow A\}
\end{gathered}
$$

Show $F_{1} \equiv F_{2}$ by using truth table 


\begin{tabular}{|c|c|c|c|c|c|c|c|c|c|}
\hline $\mathrm{A}$ & $\mathrm{B}$ & $\mathrm{C}$ & $\mathrm{D}$ & $A \wedge B \rightarrow D$ & $C \wedge D \rightarrow B$ & $C \wedge D \rightarrow A$ & $A \rightarrow B$ & $D \rightarrow C$ & $F 1$ \\
\hline $\mathrm{F}$ & $\mathrm{F}$ & $\mathrm{F}$ & $\mathrm{F}$ & $\mathrm{T}$ & $\mathrm{T}$ & $\mathrm{T}$ & $\mathrm{T}$ & $\mathrm{T}$ & $\mathrm{T}$ \\
\hline $\mathrm{F}$ & $\mathrm{F}$ & $\mathrm{F}$ & $\mathrm{T}$ & $\mathrm{T}$ & $\mathrm{T}$ & $\mathrm{T}$ & $\mathrm{T}$ & $\mathrm{F}$ & $\mathrm{F}$ \\
\hline $\mathrm{F}$ & $\mathrm{F}$ & $\mathrm{T}$ & $\mathrm{F}$ & $\mathrm{T}$ & $\mathrm{T}$ & $\mathrm{T}$ & $\mathrm{T}$ & $\mathrm{T}$ & $\mathrm{T}$ \\
\hline $\mathrm{F}$ & $\mathrm{F}$ & $\mathrm{T}$ & $\mathrm{T}$ & $\mathrm{T}$ & $\mathrm{F}$ & $\mathrm{F}$ & $\mathrm{T}$ & $\mathrm{T}$ & $\mathrm{F}$ \\
\hline $\mathrm{F}$ & $\mathrm{T}$ & $\mathrm{F}$ & $\mathrm{F}$ & $\mathrm{T}$ & $\mathrm{T}$ & $\mathrm{T}$ & $\mathrm{T}$ & $\mathrm{T}$ & $\mathrm{T}$ \\
\hline $\mathrm{F}$ & $\mathrm{T}$ & $\mathrm{F}$ & $\mathrm{T}$ & $\mathrm{T}$ & $\mathrm{T}$ & $\mathrm{T}$ & $\mathrm{T}$ & $\mathrm{F}$ & $\mathrm{F}$ \\
\hline $\mathrm{F}$ & $\mathrm{T}$ & $\mathrm{T}$ & $\mathrm{F}$ & $\mathrm{T}$ & $\mathrm{T}$ & $\mathrm{T}$ & $\mathrm{T}$ & $\mathrm{T}$ & $\mathrm{T}$ \\
\hline $\mathrm{F}$ & $\mathrm{T}$ & $\mathrm{T}$ & $\mathrm{T}$ & $\mathrm{T}$ & $\mathrm{T}$ & $\mathrm{F}$ & $\mathrm{T}$ & $\mathrm{T}$ & $\mathrm{F}$ \\
\hline $\mathrm{T}$ & $\mathrm{F}$ & $\mathrm{F}$ & $\mathrm{F}$ & $\mathrm{T}$ & $\mathrm{T}$ & $\mathrm{T}$ & $\mathrm{F}$ & $\mathrm{T}$ & $\mathrm{F}$ \\
\hline $\mathrm{T}$ & $\mathrm{F}$ & $\mathrm{F}$ & $\mathrm{T}$ & $\mathrm{T}$ & $\mathrm{T}$ & $\mathrm{T}$ & $\mathrm{F}$ & $\mathrm{F}$ & $\mathrm{F}$ \\
\hline $\mathrm{T}$ & $\mathrm{F}$ & $\mathrm{T}$ & $\mathrm{F}$ & $\mathrm{T}$ & $\mathrm{T}$ & $\mathrm{T}$ & $\mathrm{F}$ & $\mathrm{T}$ & $\mathrm{F}$ \\
\hline $\mathrm{T}$ & $\mathrm{F}$ & $\mathrm{T}$ & $\mathrm{T}$ & $\mathrm{T}$ & $\mathrm{F}$ & $\mathrm{T}$ & $\mathrm{F}$ & $\mathrm{T}$ & $\mathrm{F}$ \\
\hline $\mathrm{T}$ & $\mathrm{T}$ & $\mathrm{F}$ & $\mathrm{F}$ & $\mathrm{F}$ & $\mathrm{T}$ & $\mathrm{T}$ & $\mathrm{T}$ & $\mathrm{T}$ & $\mathrm{F}$ \\
\hline $\mathrm{T}$ & $\mathrm{T}$ & $\mathrm{F}$ & $\mathrm{T}$ & $\mathrm{T}$ & $\mathrm{T}$ & $\mathrm{T}$ & $\mathrm{T}$ & $\mathrm{F}$ & $\mathrm{F}$ \\
\hline $\mathrm{T}$ & $\mathrm{T}$ & $\mathrm{T}$ & $\mathrm{F}$ & $\mathrm{F}$ & $\mathrm{T}$ & $\mathrm{T}$ & $\mathrm{T}$ & $\mathrm{T}$ & $\mathrm{F}$ \\
\hline $\mathrm{T}$ & $\mathrm{T}$ & $\mathrm{T}$ & $\mathrm{T}$ & $\mathrm{T}$ & $\mathrm{T}$ & $\mathrm{T}$ & $\mathrm{T}$ & $\mathrm{T}$ & $\mathrm{T}$ \\
\hline
\end{tabular}

TABLE IV. TRUTH TABLE OF F2

\begin{tabular}{|c|c|c|c|c|c|c|c|c|}
\hline $\mathrm{A}$ & $\mathrm{B}$ & $\mathrm{C}$ & $\mathrm{D}$ & $A \rightarrow D$ & $D \rightarrow B$ & $D \rightarrow A$ & $A \rightarrow C$ & $F 2$ \\
\hline $\mathrm{F}$ & $\mathrm{F}$ & $\mathrm{F}$ & $\mathrm{F}$ & $\mathrm{T}$ & $\mathrm{T}$ & $\mathrm{T}$ & $\mathrm{T}$ & $\mathrm{T}$ \\
\hline $\mathrm{F}$ & $\mathrm{F}$ & $\mathrm{F}$ & $\mathrm{T}$ & $\mathrm{T}$ & $\mathrm{F}$ & $\mathrm{F}$ & $\mathrm{T}$ & $\mathrm{F}$ \\
\hline $\mathrm{F}$ & $\mathrm{F}$ & $\mathrm{T}$ & $\mathrm{F}$ & $\mathrm{T}$ & $\mathrm{T}$ & $\mathrm{T}$ & $\mathrm{T}$ & $\mathrm{T}$ \\
\hline $\mathrm{F}$ & $\mathrm{F}$ & $\mathrm{T}$ & $\mathrm{T}$ & $\mathrm{T}$ & $\mathrm{F}$ & $\mathrm{F}$ & $\mathrm{T}$ & $\mathrm{F}$ \\
\hline $\mathrm{F}$ & $\mathrm{T}$ & $\mathrm{F}$ & $\mathrm{F}$ & $\mathrm{T}$ & $\mathrm{T}$ & $\mathrm{T}$ & $\mathrm{T}$ & $\mathrm{T}$ \\
\hline $\mathrm{F}$ & $\mathrm{T}$ & $\mathrm{F}$ & $\mathrm{T}$ & $\mathrm{T}$ & $\mathrm{T}$ & $\mathrm{F}$ & $\mathrm{T}$ & $\mathrm{F}$ \\
\hline $\mathrm{F}$ & $\mathrm{T}$ & $\mathrm{T}$ & $\mathrm{F}$ & $\mathrm{T}$ & $\mathrm{T}$ & $\mathrm{T}$ & $\mathrm{T}$ & $\mathrm{T}$ \\
\hline $\mathrm{F}$ & $\mathrm{T}$ & $\mathrm{T}$ & $\mathrm{T}$ & $\mathrm{T}$ & $\mathrm{T}$ & $\mathrm{F}$ & $\mathrm{T}$ & $\mathrm{F}$ \\
\hline $\mathrm{T}$ & $\mathrm{F}$ & $\mathrm{F}$ & $\mathrm{F}$ & $\mathrm{F}$ & $\mathrm{T}$ & $\mathrm{T}$ & $\mathrm{F}$ & $\mathrm{F}$ \\
\hline $\mathrm{T}$ & $\mathrm{F}$ & $\mathrm{F}$ & $\mathrm{T}$ & $\mathrm{T}$ & $\mathrm{F}$ & $\mathrm{T}$ & $\mathrm{F}$ & $\mathrm{F}$ \\
\hline $\mathrm{T}$ & $\mathrm{F}$ & $\mathrm{T}$ & $\mathrm{F}$ & $\mathrm{F}$ & $\mathrm{T}$ & $\mathrm{T}$ & $\mathrm{T}$ & $\mathrm{F}$ \\
\hline $\mathrm{T}$ & $\mathrm{F}$ & $\mathrm{T}$ & $\mathrm{T}$ & $\mathrm{T}$ & $\mathrm{F}$ & $\mathrm{T}$ & $\mathrm{T}$ & $\mathrm{F}$ \\
\hline $\mathrm{T}$ & $\mathrm{T}$ & $\mathrm{F}$ & $\mathrm{F}$ & $\mathrm{F}$ & $\mathrm{T}$ & $\mathrm{T}$ & $\mathrm{F}$ & $\mathrm{F}$ \\
\hline $\mathrm{T}$ & $\mathrm{T}$ & $\mathrm{F}$ & $\mathrm{T}$ & $\mathrm{T}$ & $\mathrm{T}$ & $\mathrm{T}$ & $\mathrm{F}$ & $\mathrm{F}$ \\
\hline $\mathrm{T}$ & $\mathrm{T}$ & $\mathrm{T}$ & $\mathrm{F}$ & $\mathrm{F}$ & $\mathrm{T}$ & $\mathrm{T}$ & $\mathrm{T}$ & $\mathrm{F}$ \\
\hline $\mathrm{T}$ & $\mathrm{T}$ & $\mathrm{T}$ & $\mathrm{T}$ & $\mathrm{T}$ & $\mathrm{T}$ & $\mathrm{T}$ & $\mathrm{T}$ & $\mathrm{T}$ \\
\hline
\end{tabular}

table 3 is the corresponding truth table of F1 and table 4 is the corresponding truth table of F2..F1 and F2 have same value under the same assigned truth value to A,B,C,D,so $F_{1} \equiv F_{2}$

\section{CONCLUSION}

the consistency of rules of inference between Armstrong's axioms and prepositional logic means that the theory and methods about logic can be used to study FD. Two equivalent propositions have the same truth table, so two sets of FDs are equivalent if and only if their corresponding propositions have the same truth table. The equivalence of sets of FDs can be judged immediately and directly after their truth table are constructed. This approach needn't to test if every FD in one set of FDs can be derived from another anymore. But when the number of attributes is great, the numbers of rows and columns of truth table are also great, and constructing truth table is trouble and time_ consuming. This is a shortcoming which can be partly overcomed by using conjunctive normal form of logic instead of truth table. The new way proposed in this paper is possible to be used to compute minimum set of FDs, etc. 


\section{REFERENCES}

[1] E.F.Codd, "A relational model of data for large shared data banks," CACM 13,No6, June 1970,377-387

[2] W.W.Armstron, "Dependency structures of data base relationships," Proceedings of the IFIP Congress, 1974

[3] C.Delobel, R.G. Casey, "Decomposition of a data base and the theory of boolean switching functions," IBM Journal of Research and Development 1973,17(5):374-386

[4] R.Fagin, "Functional dependencies in a relational database and propositional logic,” IBM Journal of research and development 1977, 21(6): 534-544
[5] Y. Sagiv, C. Delobel, D.S. Parker,(etal), “An equivalence between relational database dependencies and a fragment of propositional logic," Journal of the Association for Computing Machinery,1981,28(3):435-453

[6] T.Ibaraki, A.Kogan, K.Makino, "Functional dependencies in Horn theories,” Artificial Intelligence 1999,108(1-2):1-30

[7] D. J. Russomanno , R.D. Bonnell, "A pedagogical approach to database design via Karnaugh maps,” IEEE Transactions on Education, 1999, 42(4): 261-269

[8] A.Mora, G.Aguilera, M.Enciso, P.Cordero, I.P.de Guzman, “A new closure algorithm based in logic: SLFD-Closure versus classical closures ,” Intelligence Artificial, 2006,10(31):31-40 